\title{
Exploring Synchronicity in the Heart Rates of Familiar and Unfamiliar Pairs of Horses and Humans Undertaking an In-Hand Task
}

\author{
Jo Hockenhull, Tamsin J. Young, Sarah E. Redgate \& Lynda Birke
}

To cite this article: Jo Hockenhull, Tamsin J. Young, Sarah E. Redgate \& Lynda Birke (2015) Exploring Synchronicity in the Heart Rates of Familiar and Unfamiliar Pairs of Horses and Humans Undertaking an In-Hand Task, Anthrozoös, 28:3, 501-511, DOI: 10.1080/08927936.2015.1052284

To link to this article: http://dx.doi.org/10.1080/08927936.2015.1052284

Published online: 06 Oct 2015.

Submit your article to this journal

Џ Article views: 38

View related articles $\sqsubset$

View Crossmark data $\asymp$ 


\section{Exploring Synchronicity in the Heart Rates of Familiar and Unfamiliar Pairs of Horses and Humans Undertaking an In-Hand Task}

*Address for correspondence: Jo Hockenhull, Animal Welfare and Behaviour Group, School of Veterinary Sciences, University of Bristol, Langford House, Langford, Bristol BS40 5DU, UK. E-mail: Jo.Hockenhull@bristol.ac.uk

\author{
Jo Hockenhull ${ }^{\star}$ Tamsin J. Young ${ }^{\dagger}$, Sarah E. Redgate ${ }^{\ddagger}$ \\ and Lynda Birke $\$$ \\ 'School of Veterinary Sciences, University of Bristol, UK \\ ${ }^{\dagger}$ Biology and Environment, Glyndwr University, UK \\ FSchool of Animal, Rural and Environmental Sciences, Nottingham \\ Trent University, UK \\ ${ }^{\S}$ Department of Biological Sciences, University of Chester, UK
}

ABSTRACT Physiological responses that occur in horses and humans during their interactions, on the ground and during ridden work, have been investigated in a number of studies with some conflicting results. These suggest that in some situations emotional state may be transferred from humans to horses and that there is the potential for the heart rates of horse-human pairs to become synchronized during ridden work. Here we explore the effect of familiarity on the physiological responses of horse-human pairs completing a task in-hand, using heart rate as an indicator for emotional state. We investigated differences in heart rate response between familiar and unfamiliar pairings and the possibility of heart rate synchronization within each pair. Complete sets of horse and human heart rate data were available for 17 horses. We found a significant order affect, with higher horse heart rates seen the first time around the course regardless of whether a familiar or unfamiliar handler was leading (Wilcoxon test: $Z=-2.67, p<0.05)$. However, despite this, the horses' mean heart rates for each course were significantly higher with the unfamiliar handler than with the familiar handler (Wilcoxon test: $Z=-4.46, p<0.001$ ). In contrast, human heart rates were higher when paired with a familiar horse compared with an unfamiliar horse (Mann-Whitney $U$ test: $Z=-5.08, p<0.001$ ). Significant correlations between horse and human heart rates were seen in three familiar pairings and two unfamiliar pairings. Our findings indicate that the relationship between horse and human heart rates during interactions is not straightforward or consistent between horses and humans, and is likely to depend on a number of factors such as experience of the test situation. Although 
the lower heart rates seen in horses being led by their familiar handler suggest that they are more relaxed with someone they know, this could not be said for the human partner.

Keywords: anxiety, familiarity, heart rate, horse-human relationship, synchronicity

As people who care for, spend time with, and/or ride horses, one thing we seek is a close bond with an individual horse. We have grown up with this ideal percolating the majority of children's fictional equestrian literature, for example, My Friend Flicka (O'Hara 1941) and The Black Stallion (Farley 1941).

Outside of the realms of fiction, this ideal has manifested itself in the wave of "natural horsemanship" training philosophies and approaches that have emerged over recent years. While there are differences in the types of language used and the exact practices promoted by proponents of each approach, these philosophies are typically marketed as means by which communication with horses, and therefore the horse-human relationship can be improved above and beyond that which can be achieved through more "traditional" training practices (Parelli 1993; Roberts 1997; Birke 2008). The popularity of these approaches provides strong evidence of people's desire to enhance their relationship with their horse, something which has been further substantiated through ethnographic investigations in this area (Brandt 2004; Birke 2007, 2008; Keaveney 2008).

Scientific study has also turned toward the horse-human relationship in the desire to develop a greater understanding of how horses and humans interact. These studies have used observations of equine behavior, often in conjunction with physiological measures, to explore different facets of the horse-human relationship; although, it should be noted that physiological measures do not always correlate with behavioral observations (e.g., see Yarnell, Hall and Billett 2013). One area that has received attention is whether nervousness can be transmitted from rider to horse. For a long time many people who own or work with horses have taken this as fact (Keaveney 2008), but it has received relatively little scientific attention. As fearful behavior from horses is a common cause of horse-riding accidents (Keeling and Ladewig 2010), research into the transmission of emotional state between horse and human has important implications for rider safety and horse welfare, as well as the potential for improving competitive performance (Peeters et al. 2013). Studies in this area have typically used changes in horse heart rate as an indicator of psychological changes (Keeling, Jonare and Lanneborn 2009), although additional physiological measures such as heart rate variability and cortisol release have also been used (Becker-Birck et al. 2012; Ille et al. 2013).

While Keeling, Jonare and Lanneborn (2009) found evidence that rider nervousness was transmitted to the horse during a ridden experimental task when the riders were expecting something potentially frightening to happen, studies based on measures taken during normal ridden work in a training and/or performance environment did not find a similar relationship. Increased heart rate and cortisol levels of riders did not appear to equate to a correspondingly high increase in the heart rate and cortisol levels of their horses (Becker-Birck et al. 2012; Ille et al. 2013; von Lewinski et al. 2013), indicating that in the training/performance environment horses may not respond physiologically to the nervousness of their riders.

Factors likely to affect the nerves of people interacting with horses, including their attitude and experience, have also been investigated for their effect on the horse. Behavioral and physiological changes have been observed in horses when handled from the ground by people with a negative or positive attitude toward them, suggesting that horses can discriminate between 
people with different attitudes (Hama, Yogo and Matsuyama 1996; Chamove, Crawley-Hartrick and Stafford 2002). However, in both of these studies handler attitude was fundamentally determined by their experience and confidence in handling horses, and only a limited number of horses were used ( $n=1$ and $n=2$, respectively).

The effect of human experience on the horse's physiology has also been studied in the context of ridden work, but no evidence was found for a difference in stress response when the horse was ridden by experienced riders in comparison with being ridden by inexperienced riders (Ille et al. 2013). However, the authors qualified their findings by stating that both groups had some degree of experience with horses and the results might not be the same if the horse's response to experienced riders was compared with that resulting from being ridden by true beginners (Ille et al. 2013).

These studies raise the question of whether the handlers' experience with horses is the important factor in the impact they have on the horse's physiology and/or behavior, or is it their confidence, attitude, or a combination of these factors? And what of familiarity - the handlers' experience of that specific horse and the relationship they have between them? There has been some suggestion that rider familiarity, rather than experience per se, may have an influence on equine fear responses (König von Borstel and Krienert 2012) and that the heart rates of established, competing horse-rider pairs can become synchronized during the undertaking of a dressage test (Bridgeman, Pretty and Terry 2011). However, the effect of familiarity on physiological responses of horses and humans during their interactions from the ground has not been explored.

Heart rate $(\mathrm{HR})$ was chosen as the physiological measure of horse's emotional reactivity during the obstacle course, as it has been successfully used for similar purposes in other studies (e.g., equine reactivity to novel objects, Visser et al. 2002; and quantifying equine temperament, Visser et al. 2003). Both HR and heart rate variability (HRV) represent the net interaction between vagal (reducing HR) and sympathetic (increasing HR) regulation, and von Borell et al. (2007) suggests both to be suitable measures of emotional reactivity in varying animal species. Their findings do, however, suggest HRV could be a more accurate measure of sympathovagal balance, but urge caution in its use, suggesting data from at least 5 minutes of recording is necessary, and the age and sex of participants should be standardized together with time of day. Within subjects data collection is also deemed more meaningful than between subjects. Since this study made use of a variety of different horses from which data were collected in the presence of familiar and unfamiliar handlers, and immediate measures of HR were necessary at set points, it was deemed that HR would serve as a suitable physiological indicator of emotional reactivity.

The aim of this study was to investigate the effect of horse and handler familiarity on the heart rate of both parties during completion of an in-hand task. We also wanted to see if synchronization of horse-human heart rates occurs when working together in-hand rather than under saddle, and if so, whether this phenomenon is found in both familiar and unfamiliar pairings.

\section{Methods}

The study received ethical approval from the University of Chester, Department of Psychology Ethics Committee. We recruited 21 human volunteers (hereafter "handlers") and their horses from four different UK equestrian establishments between June 2010 and September 2012, through a network of personal contacts who themselves recruited volunteers in person at their respective locations and from their own horse-owning contacts. All volunteers were given an 
Table 1. Details of the 17 horses used in the study for whom a complete set of heart rate data were available.

\begin{tabular}{lcccccc}
\hline Horse ID & Location & $\begin{array}{c}\text { Age } \\
\text { (Years) }\end{array}$ & $\begin{array}{c}\text { Length } \\
\text { of Time } \\
\text { with Familiar } \\
\text { Person (Years) }\end{array}$ & Sex & Breed/Type ${ }^{\text {b }}$ & $\begin{array}{c}\text { Height } \\
\text { (Hands/lnches) }\end{array}$ \\
\hline 1 & 1 & 11 & 6.0 & M & TB & 16.0 \\
2 & 1 & 9 & 2.0 & G & ISH & 15.2 \\
3 & 1 & 24 & 4.0 & G & TB & 15.2 \\
4 & 1 & 25 & 7.0 & G & DWB & 16.3 \\
5 & 1 & 17 & 4.0 & M & BWB $\times$ Han & 16.0 \\
6 & 2 & 18 & 14.0 & G & ISH & 16.1 \\
7 & 2 & 8 & 6.0 & G & Exmoor & 12.2 \\
8 & 2 & 12 & 0.5 & M & TB & 15.0 \\
9 & 2 & 6 & 5.0 & M & Exmoor & 12.3 \\
10 & 3 & 16 & 0.5 & G & Sec D $\times$ Trotter & 15.0 \\
11 & 3 & 5 & 1.0 & G & Gypsy Vanner & 14.2 \\
12 & 3 & 16 & 0.8 & G & ISH & 16.3 \\
13 & 3 & 14 & 5.0 & M & Sec B & 13.0 \\
14 & 4 & 7 & 3.0 & G & Mixed Breeding & $?$ \\
15 & 4 & 22 & 7.0 & G & ISH & 16.1 \\
16 & 4 & 2 & 0.5 & G & Gypsy Vanner & 13.1 \\
17 & 4 & 11 & 2.0 & M & Connemara & 14.2 \\
\hline
\end{tabular}

aLocation of testing: 1 = livery yard June 2010; 2 = private yard September 2012; 3 = livery yard September 2012; 4 = livery yard March 2011.

' $\mathrm{ISH}=$ Irish Sports Horse; TB = Thoroughbred; DWB = Dutch Warm Blood; BWB = British Warm Blood; Han = Hanoverian; Sec B or D = Welsh Section B or D.

information sheet containing details about the study and how the data would be used, and were asked for their consent to participate.

\section{Study Design}

Handlers were asked to lead their own or an unfamiliar horse around a course marked out in an enclosed arena (approximately $20 \mathrm{~m}$ wide $\times 40$ or $60 \mathrm{~m}$ long). All horses were familiar with the arena used, with the exception of horses 7 and 9 at location 2 (see Table 1). Three of the arenas were outdoors and one was indoors.

The course was designed to promote interaction between horse and handler by including obstacles to negotiate and changes in pace and direction, requiring the pair to make a number of turns and adjustments in terms of their position alongside each other. The course was completed in walk with the exception of four trot strides toward the end. The course is outlined in Figure 1. After an initial circle around the outside of the arena, the pair entered the chicane (A), then walked around to a "gate" marked by two cones (B) where the handlers were asked to halt and then move the horse backwards four steps. They then walked forwards and went in and out of the cones (the slalom, C), and then through three more "gates" (D). The pair then circled around the arena so they were alongside the slalom cones (C) where they were asked to trot for four strides before returning to the set-up point. All horses were led in a head collar and lead rope. The circuit took approximately 5 minutes to complete. 


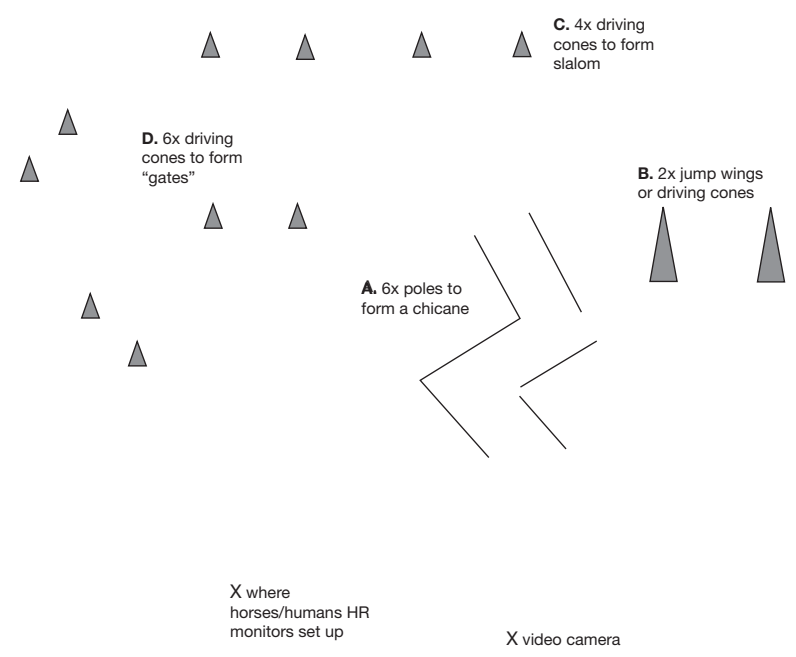

Figure 1. The layout of the course completed in walk (in an anticlockwise direction) by all horse-handler pairs, with the exception of four strides of trot which occurred alongside the slalom (C).

Each horse was led around the course two times, once by a familiar handler and once by an unfamiliar handler, in a cross-over design with stratified random sampling so that 11 horses were first led by a familiar handler and 10 by an unfamiliar handler. There was a short break of approximately 5 minutes between rounds during which the horse was asked to stand at the set-up point. Both handlers were present throughout and able to observe each other's rounds; this was to allow the handlers to discuss their perceptions of how the horse went for them and the other handler in a brief interview conducted after the horse had completed both rounds of the course (see Birke and Hockenhull 2015). All horses and handlers wore Polar RS800 heart rate monitors whilst undertaking the course. The data loggers for each monitor were positioned as close as possible to the monitor for both horse (on the surcingle around the horse's girth) and handler (on the handler's wrist). No interference between the two heart rate monitors was observed. Each round was videoed for subsequent behavioral analysis and this has been reported elsewhere (see Birke and Hockenhull 2015).

Due to recording issues with either the horse or the human heart rate monitors, heart rate data were ultimately available for 17 of the 21 horses and their familiar and unfamiliar handlers, with each horse that was missing heart rate data or lacked heart rate data from one or both of their handlers being excluded from the analyses.

\section{Participants}

Horses: Heart rate (HR) was measured from 17 horses whose ages ranged from 2 to 25 years (Table 1). The horses' median age was 12 years, with an interquartile range (IQR) of 7.5-17.5 years. The horses included a variety of breeds spanning natives to thoroughbreds. The length of time the horses had known their familiar handler ranged from 6 months to 14 years, with a median (IQR) of 4 years (0.88-6 years).

Handlers: All handlers were required to have experience of, and be confident in handling, horses. This was ascertained through discussion with the people involved. In total, 22 different handlers were used in this study; 16 of these were familiar handlers who led their own 
Table 2. Details of the familiar and unfamiliar handlers used with each horse in the study.

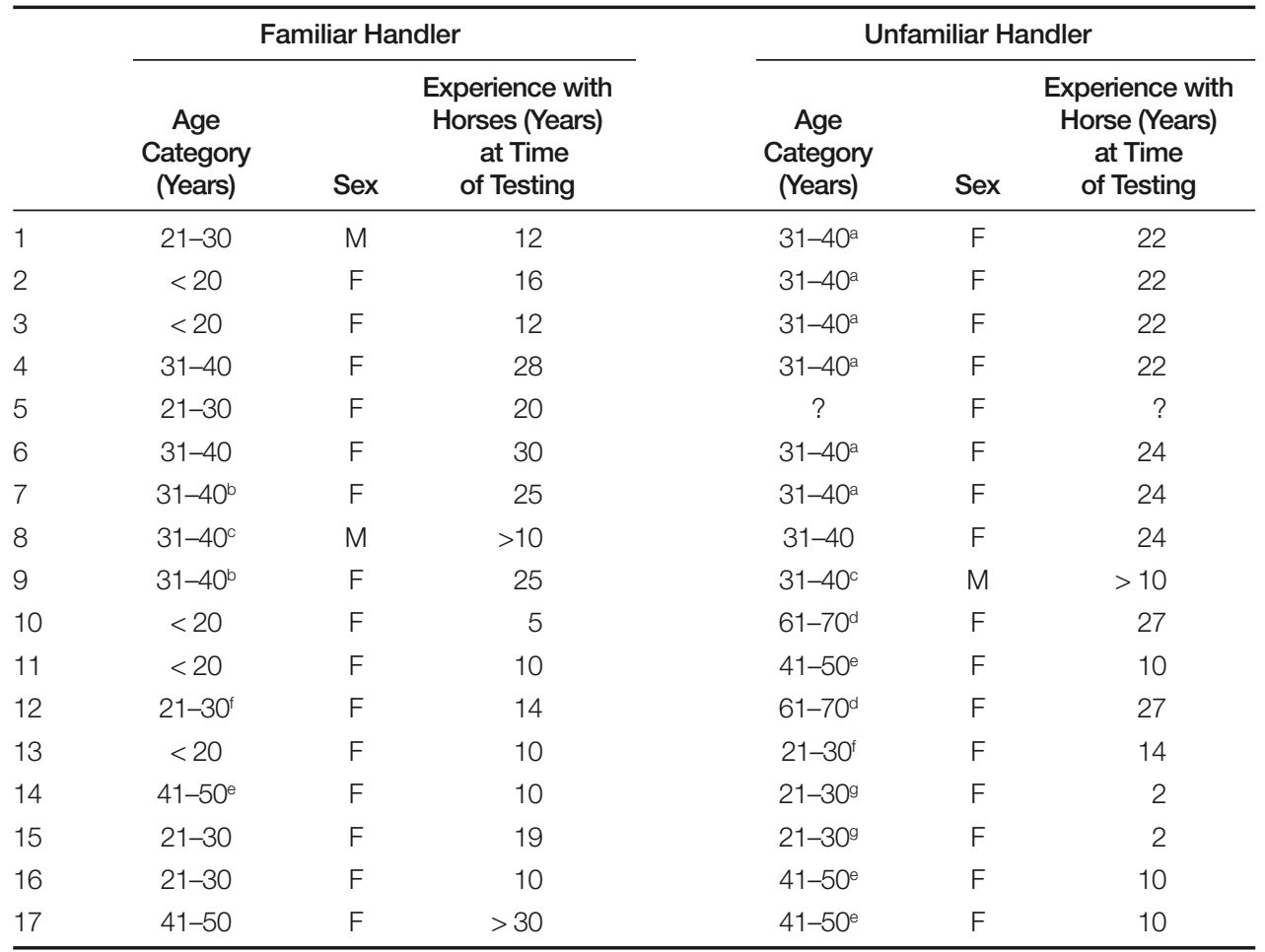

a,b,c,d,e,f,g Letter denotes the same handler.

horse (one handler led two of her own horses) (Table 2). The unfamiliar handlers were a convenience sample, typically people present at the location or the time of the study who were not familiar with the study horse. In three instances the unfamiliar person also completed the test as a familiar handler with their own horse, and three handlers only led unfamiliar horses. Handler age ranged from < 20 to 61-70 years, with a median (IQR) of 21-30 ( $<20-31-40)$ years. Their horse experience ranged from 2 years to over 30 years, with a median (IQR) of 14 (10-24.25) years. Only two of the handlers were male, reflecting the bias toward women owners/carers in the UK leisure-horse population (Boden et al. 2013; Hockenhull and Creighton 2013). It has been suggested that human gender does not impact on horse behavior (Henry et al. 2005; Hausberger et al. 2008) and therefore no efforts were made to address the sex bias in our handlers.

\section{Data}

The heart rate monitors were set up to record beats per minute (bpm) calculated every 5 seconds. The monitors were started immediately before the horse and handlers undertook the course and were stopped as soon as they finished it. Absolute heart rate was used to aid comparison with similar studies of horse-human interactions (e.g., Keeling, Jonare and Lanneborn 2009; Bridgeman, Pretty and Terry 2011; Merkies et al. 2012). Heart rate variability was not used due to the short test duration ( $\leq 5$ minutes) and because the focus of the study was on the acute heart rate response to the test situation, rather than a longer-term exploration of the stress response. 


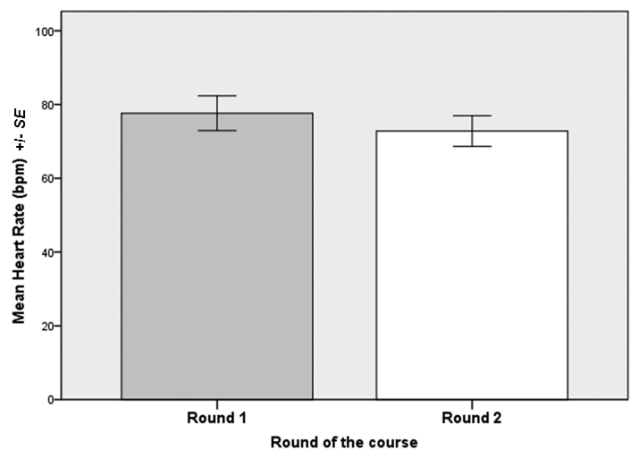

Figure 2. Mean heart rate (bpm) of the horses as they completed the first and second rounds of the course.

Once the heart rate data were downloaded, the heart rates of the horse and handler at 16 set points over the course were noted and these values, and the average derived from them for each participant, were used for the analysis.

\section{Statistical Analyses}

Prior to analysis the data were tested for normality using the Shapiro-Wilk test. Data were not normally distributed and consequently non-parametric analyses were used. Wilcoxon Signed Rank Tests were used to explore whether there was any effect of the order in which the horse completed the course, irrespective of familiarity of the hander, on the mean heart rates of the horses, and whether there was any difference in the mean heart rates of horses with the familiar and unfamiliar handlers. Mann-Whitney $U$ tests were used to compare handler heart rates when leading a familiar or unfamiliar horse. Spearman's Rank Order Correlations using the heart rates for horse and handler noted at the 16 set points of the course were used to explore the relationship between the horse and handler heart rates to determine synchronicity. All statistical analyses were conducted using SPSS for Windows v14 (SPSS Inc, USA).

\section{Results}

\section{Comparison of Handler Groups}

Due to the overlap between familiar and unfamiliar handler groups, it was inappropriate to statistically test for differences in age and experience between the groups. However, descriptive analysis of the median (IQR) showed that the groups were comparable in terms of age and experience with horses. The median (IQR) age of the familiar handlers was 21-30 $(<20-31-40)$ years, with a median (IQR) of 13 (10-23.25) years' experience with horses. In comparison, the median (IQR) age of unfamiliar handlers was slightly higher at 31-40 (21-30-41-50) years, although their experience with horses was very similar, with a median of 12 (10-23.50) years.

\section{Effect of Order of Course Completion on Horse Heart Rate}

There was a significant difference in horses' HR (bpm) between the two rounds of the course (Wilcoxon test: $Z=-2.67, p=0.008$ ). When they completed the course for a second time their mean HR was lower than during their first round, regardless of whether the handler was familiar or unfamiliar (Figure 2). 


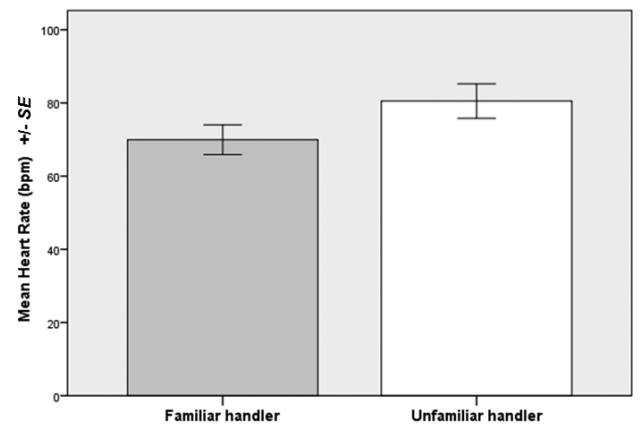

Figure 3. Mean heart rate (bpm) of the horses when led by a familiar and an unfamiliar handler.

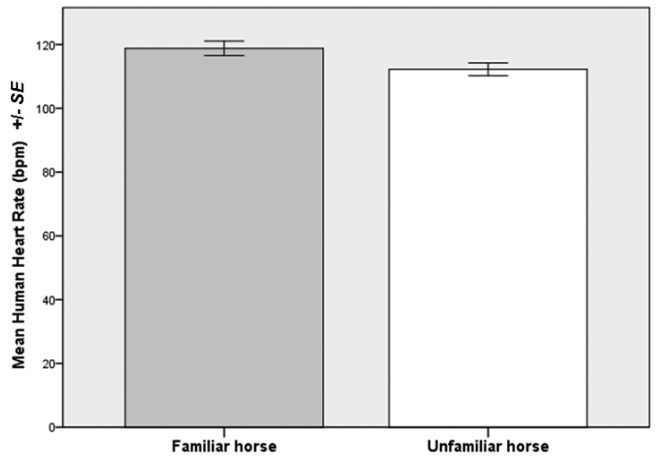

Figure 4. Mean heart rate (bpm) of the handlers when leading a familiar or an unfamiliar horse.

\section{Effect of Familiarity of Handler on Horse Heart Rate}

Despite a significantly lower HR being recorded in horses completing the obstacle course for a second time, when horses were handled by an unfamiliar handler, regardless of whether this was for their first or second round of the course, they experienced a significantly higher mean $H R$, as compared with when they were handled by a familiar handler Wilcoxon test: $Z=-4.46$, $p<0.001$; see Figure 3).

\section{Effect of Familiarity of Horse on Handler Heart Rate}

When handlers were leading horses familiar to them, their HR was significantly higher than when they were leading horses unfamiliar to them (Mann-Whitney $U$ test: $Z=-5.08, p<0.001$; see Figure 4).

\section{Does Horse and Handler HR Correlate During the Course?}

Of the 17 horses that completed the obstacle course, the HR of four of the horses correlated significantly with the handler they were familiar with (Spearman's Rank Order Correlation: Horse 3: $r=-0.68, n=16, p=0.004$; Horse 5: $r=0.55, n=15, p=0.035$; Horse 7: $r=0.52$, $n=15, p=0.048$; Horse 10: $r=0.63, n=15, p=0.011$ ).

The HR of two of the horses correlated significantly with the unfamiliar handler (Spearman's Rank Order Correlation: Horse 7: $r=0.77, n=15, p=0.001$; Horse 16: $r=-0.56$, $n=15, p=0.029$ ). 


\section{Discussion}

The familiarity of horse and handler appears to have an effect on the heart rate of both horses and humans during the completion of an in-hand task; however, this effect cannot be explained by familiarity alone.

First, the finding of an order effect, whereby horses had a significantly lower mean heart rate on their second round of the course, regardless of who was leading them compared with their first round, was not entirely unexpected but does have important implications for other studies of this kind. We tried to minimize order effect in this study by testing the horses and handlers in a pseudo-random order; however, one pairing always had to go first and this finding highlights the need to keep potential order effects in mind when interpreting results (Martin and Bateson 1993).

Despite the presence of an order effect, the mean heart rate of horses was significantly higher when they completed the course with an unfamiliar handler. This suggests that the horses were more relaxed completing the course with a handler they knew well. The length of time that the horses had known their familiar handler ranged from 6 months to 14 years. Five of the horses had known their familiar handler $\leq 1$ year but our findings imply that this duration is long enough to build some kind of relationship with that person that distinguishes them from a handler who is experienced and confident around horses but who is unfamiliar to them. Behaviorally, there was an observable difference between familiar and unfamiliar pairings in their relaxation, coordination, and attentiveness, with familiar pairings moving together in greater harmony (Birke and Hockenhull 2015), supporting the idea of relaxation portrayed in the horse heart rate data.

However, the heart rates of the handlers did not follow the same trend as the heart rates of the horses. Handlers leading their familiar horses had a significantly higher mean heart rate than those completing the course with an unfamiliar horse. It is likely that this reflects some degree of performance anxiety on the part of the handler; that handlers are more anxious about the task when working with their own horse in what could be perceived as a test situation. In contrast, the unfamiliar handlers had less invested in the horse and may not have been as concerned about its performance and how their relationship with the horse could be judged. This hypothesis was supported in the interviews conducted with the handlers after the course had been completed (Birke and Hockenhull 2015) and informally during the period between rounds.

This finding parallels those of published studies exploring physiological differences in horses and riders between training and a public performance or competition, where the rider showed a greater physiological response, indicating heightened anxiety, in a performance situation that the authors speculated may be due to the presence of spectators and the expectations the riders placed on themselves (Becker-Birck et al. 2012; von Lewinski et al. 2013). Similar to our findings, these studies found no corresponding physiological change in their horses (BeckerBirck et al. 2012; von Lewinski et al. 2013). In contrast, Bridgeman, Pretty and Terry (2011) found that horses ridden by more anxious riders had higher heart rates themselves. The implications of heightened rider physiological response on performance differ between published studies. Peeters et al. (2013) found that increased rider stress (measured via salivary cortisol) reduced performance quality, whereas Bridgeman, Pretty and Terry (2011) found no such association. It is worth noting, however, that while there was some degree of overlap between our familiar and unfamiliar handler groups, there were three handlers who only led unfamiliar horses, and this may have affected the mean group heart rate. 
The final relationship we explored was the synchronicity of heart rates between horsehandler pairs. Here the results were mixed, with only six of the 34 pairings showing any correlation between horse and handler heart rates. Four of these significant correlations were familiar pairings and two were unfamiliar, although the horse in one of the unfamiliar pairings was also significantly correlated with his familiar handler. This contrasts with Bridgeman, Pretty and Terry (2011), who found synchronization in the heart rates of 13 out of their 17 horse-rider pairs. The difference may stem from the distinction between working with a horse on the ground, where horse and human are only connected physically via a lead rope, and working with a horse under saddle, where the rider is physically in direct contact with the horse and can communicate through their body (Keaveney 2008). Our findings provide no real evidence for heart rate synchronization in horse-handler pairs undertaking a course with the human on the ground in a test situation.

Our findings indicate that there is a complex relationship between horse and human heart rates during interactions on the ground. Familiarity appears to have a conflicting effect on horse and handler, with horses more relaxed with someone they know and handlers seemingly affected by performance anxiety when working with their familiar horse. Intangible, hard to measure factors such as previous personal experience of working with other partners or the test situation are also likely to influence the physiological response observed and should be taken into consideration in future studies of this type.

\section{Acknowledgements}

We thank the anonymous reviewers for their constructive feedback on an earlier draft of this manuscript and all horses and handlers who took the time to participate in this study.

\section{References}

Becker-Birck, M., Biau, S., Ille, N., Aurich, J., Möstl, E. and Aurich, C. 2012. Heart rate, heart rate variability and cortisol release in the horse and its rider: Different response of training and a public performance. Paper presented at the 8th International Society for Equitation Science Conference, Edinburgh, UK, July 18-20, 2012.

Birke, L. 2007. "Learning to speak horse": The culture of "natural horsemanship." Society \& Animals 15(3): 217-239.

Birke, L. 2008. Talking about horses: Control and freedom in the world of "natural horsemanship." Society \& Animals 16(2): 107-126.

Birke, L. and Hockenhull, J. 2015. Journeys together: Horses and humans in partnership. Society \& Animals 23: 81-100.

Boden, L. A., Parkin, T. D. H., Mellor, D. and Kao, R. R. 2013. An online survey of horse-owners in Great Britain. BMC Veterinary Research 9: 188.

von Borell, E., Langbein, J., Despres, G., Hansen, S., Leterrier, C., Marchant-Forde, J., Marchant-Forde, R., Minero, M., Mohr, E., Prunier, A., Valance, D. and Veissier, I. 2007. Heart rate variability as a measure of autonomic regulation of cardiac activity for assessing stress and welfare in farm animals: A review. Physiology \& Behavior 92(3): 293-316.

Brandt, K. 2004. A language of their own: An interactionist approach to human-horse communication. Society \& Animals 12(4): 299-316.

Bridgeman, D. J., Pretty, G. M. and Terry, P. C. 2011. Identifying interactive components of the horse-rider partnership during competition dressage. Paper presented at the 7th International Society for Equitation Science Conference, Hooge Mierde, The Netherlands, October 26-29, 2011.

Chamove, A. S., Crawley-Hartrick, O. J. E. and Stafford, K. J. 2002. Horse reactions to human attitudes and behaviour. Anthrozoös 15(4): 323-331.

Farley, W. 1941. The Black Stallion. New York: Random House.

Hama, H., Yogo, M. and Matsuyama, Y. 1996. Effects of stroking horses on both humans' and horses' heart rate responses. Japanese Psychological Research 38(2): 66-73. 
Hausberger, M., Roche, H., Henry, S. and Visser, E. K. 2008. A review of the human-horse relationship. Applied Animal Behaviour Science 109: 1-24.

Henry, S., Hemery, D., Richard, M.-A. and Hausberger, M. 2005. Human-mare relationships and behaviour of foals towards humans. Applied Animal Behaviour Science 93: 341-362.

Hockenhull, J. and Creighton, E. 2013. The use of equipment and training practices and the prevalence of owner-reported ridden behaviour problems in UK leisure horses. Equine Veterinary Journal 45(1): 15-19.

Ille, N., von Lewinski, M., Erber, R., Wulf, M., Aurich, J., Möstl, E. and Aurich, C. 2013. Effects of the level of experience of horses and their riders on cortisol release, heart rate and heart rate variability during a jumping course. Animal Welfare 22: 457-465.

Keaveney, S. M. 2008. Equines and their human companions. Journal of Business Research 61(5): 444-454.

Keeling, L. J., Jonare, L. and Lanneborn, L. 2009. Investigating horse-human interactions: The effect of a nervous human. The Veterinary Journal 181: 70-71.

Keeling, L. J. and Ladewig, J. 2010. Optimal injury prevention for riders: Don't fall off the horse. Paper presented at the 6th International Equitation Science Conference, Uppsala, Sweden, July 31-August 2, 2010.

König von Borstel, U. and Krienert, N. 2012. Influence of familiarity with the rider and types of work on horses' fear reactions. Paper presented at the 8th International Equitation Science Conference, Edinburgh, UK, July 18-20, 2012.

von Lewinski, M., Biau, S., Erber, R., Ille, N., Aurich, J., Faure, J.-M., Möstl, E. and Aurich, C. 2013. Cortisol release, heart rate and heart rate variability in the horse and its rider: Different responses in training and performance. The Veterinary Journal 197: 229-232.

Martin, P. and Bateson, P. 1993. Measuring Behaviour: An Introductory Guide. 2nd edn. Cambridge: Cambridge University Press.

Merkies, K., Isensee, A., MacGregor, H., von Borstel, U., Tucker, A., Carson, J. and Bergeron R. 2012. Influence of psychological and physiological arousal in humans on horse heart rate and behaviour. Paper presented at the 8th International Equitation Science Conference, Edinburgh, UK, July 18-20, 2012.

O'Hara, M. 1941. My Friend Flicka. Philadelphia: J.B. Lippincott Company.

Parelli, P. 1993. Natural Horse-man-ship. Colerado Springs, CO: Western Horseman.

Peeters, M., Closson, C., Beckers, J.-F. and Vandenheede, M. 2013. Rider and horse salivary cortisol levels during competition and impact on performance. Journal of Equine Veterinary Science 33: 155-160.

Roberts, M. C. 1997. The Man Who Listens to Horses. London: Arrow Books Ltd.

Visser, E. K., van Reenen, C. G., Rundgren, M., Zetterqvist, M., Morgan, K. and Blokhuis, H. J. 2003. Responses of horses in behaviour tests correlate with temperament assessed by riders. Equine Veterinary Journal 35(2): 176-183.

Visser, E. K., van Reenen, C. G., van der Werf, J. T. N., Schilder, M. B. H., Knaap, J. H., Barneveld, A. and Blokhuis, H. J. 2002. Heart rate and heart rate variability during a novel object test and a handling test in young horses. Physiology and Behavior 76: 289-296.

Yarnell, K., Hall, C. and Billett, E. 2013. An assessment of the aversive nature of an animal management procedure (clipping) using behavioral and physiological measures. Physiology \& Behavior 118: 32-39. 